\title{
Design and Research of Miniaturized Micro Strip Slot with and without Defected Ground Structure
}

\author{
D. Nataraj, G. Karunakar
}

\begin{abstract}
In this paper, a compact microstrip patch has a slot associated with the Defected Ground Structure radiator is presented. Instead of semi-infinite ground plane, the proposed antenna adopts the defected ground plane. The Radiating patch mendacity on the FR-4 substrate which is having dielectric constant of 4.4, thereby provides good bandwidth. This microstrip antenna is designed for wide bandwidth applications in range of $5.5 \mathrm{GHz}$ to $7.25 \mathrm{GHz}$. Proposed work introduces a methodology wherein reducing of structure's increase the bandwidth as well as return loss with defected ground structure (DGS).However since communication systems require small size, broad band and multiband antennas, monopoles have to be ensued for fabricating broad-band and wide-band antennas. In the proposed work investigations are carried out to design a new antenna with broad-band properties. Simulations are carried out via An soft HFSS electromagnetic simulator software- fabricated on FR-4 Substrate and tested with Vector network Analyzer. Measurement and Simulation results obtained prove the applicability of proposed antenna in $5.5 \mathrm{GHz}$ to $7.25 \mathrm{GHz}$ frequency range with a return loss of $-31.3 d B$ and $11.5 d B$ etc. Microstrip feed line technique is used to feed the antenna with $50 \Omega$ impedance.

Index Terms--- Defected Ground Structure (DGS) Elliptical ,Microstrip Antenna, Microstrip Slot Antenna, WiMAX, Radiation Pattern.
\end{abstract}

\section{INTRODUCTION}

Microstrip antennas are quite an obvious choice for wireless devices because of their properties, and several advantages as compared to other bulky type of antennas. Some of the main advantages of microstrip antenna are that it has low fabrication cost, light weight, low volume, and low profile configuration that can be made conformal, it can be easily mounted on rockets, missiles and any conformal shaped satellites without major modifications and arrays of these antennas can simply be produced [1]. However, the microstrip patch antennas suffer from a number of disadvantages as patch length is around half a wavelength. In recent years, the miniaturization of antennas has become more and more important due to the increasing demand for small antennas as the rapid development in wireless communications. Many efforts have also been made in order to achieve the size reduction like using planar inverted $\mathrm{F}$ antenna structure (PIFA) [2] or using a dielectric substrate of high permittivity [3], defected microstrip structure (DMS) [4], defected ground structure (DGS) [5], or a combination of them.

Mainly DGS is an etched periodic or non-periodic

\footnotetext{
Manuscript received September 16, 2019.

D. Nataraj, Associate Professor, Dept of ECE, Pragati Engineering College (A3), Surampalem, Kakinada, A.P, India,Email:dasari.nataraj@gmail.com

Dr. G. Karunakar, Associate Professor, Dept of ECE, Gitam Institute of Technology, GITAM University, Vizag, A.P, India.
} cascaded configuration defect in ground of a planar

transmission line (e.g., microstrip, coplanar and conductor backed coplanar wave guide) which disturbs the shield current distribution in the ground plane because of the defect in the ground .The defect geometry is easy to implement and does not need a large area. These features enable such structures to acquire a great relevance in microwave circuit design [6]. In particular, DGS is employed to design microstrip antennas for different applications, for instance, cross polarization, mutual coupling reduction in antenna arrays and harmonic suppression. Moreover, DGS has been widely used in the development of miniaturized antennas [7].

In this paper DGS is used to design a miniaturized microstrip patch antenna with slot and with \&without DGS. Initially the proposed typical rectangular microstrip patch array antenna designed at $\mathrm{C}$ band, resonates at $5.5 \mathrm{GHz}$. However it is further miniaturized by introducing the new DGS to shift the resonance frequency from $\mathrm{C}$ band to $\mathrm{S}$ band keeping the physical volume of the antenna constant. This size reduction significant reduces the gain and degrades the antenna performance due to the increase in ohmic losses. Further in order to enhance the antenna performance with size reduction, it has been proposed to modify the patch radiator of the typical rectangular antenna with the same DGS structure.

The defected ground structure (DGS) and the Electromagnetic band gap structures(PBG) are the two different type soft hegeneric structures mostly used for the design of compact and high performance microwave components [8]. These structures are employed to reject unwanted frequency and circuit size reduction. DGS is an etched lattice of certain shape located on the ground plane. The performance of microstrip antennas and their array can be enhanced by introducing the defects in the ground plane [9]. The shape of the defect may be changed from the simple shape to the complicated shape for better performance. The DGS equivalent circuit consists of a parallel tuned circuit in series with the transmission line to which it is coupled as shown in Fig. 5. The different shapes of DGS structure have the same role and same characteristics of slow wave effect and high impedance, band rejection, miniaturization of size with the same equivalent circuit [10].

Micro strip patch antennas possess several advantages and better prospects, which include for instance light weight, lower cost and smaller dimensions. They can be easily designed to operate in dual and multi band applications - for dual or circular polarization.

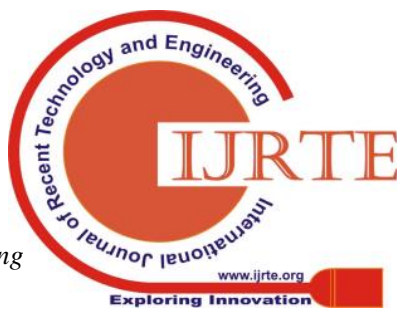




\section{DESIGN AND RESEARCH OF MINIATURIZED MICRO STRIP SLOT WITH AND WITHOUT DEFECTED GROUND STRUCTURE}

Micro strip patch antennas are predominantly used in medical applications, satellites and military systems etc. However the rapid advancements in wireless communication based applications, much efforts are devoted to reduce the size of micro strip patch antennas. Several novel methods are proposed in the design of micro strip patch antennas like using a dielectric substrate of high permittivity, Defected Micro strip Structure (DMS), Defected Ground Structure (DGS) at the ground plane or their combination. Defected Ground Structure (DGS) is a periodic or non periodic cascaded defect configuration etched in the ground plane of planar transmission line, the defect geometry is easy to implement requiring small area.

\section{ANTENNA DESIGN}

In defected Ground Structure (DGS) based micro strip antenna, the defect geometry (etched in ground plane) disturbs its current distribution- which further affects the transmission line characteristics such as capacitance and inductance. In other words, the introduction of DGS increased the effective capacitance and inductance to further influence the Impedance and current flow in antenna there by reducing its size with respect to the given resonance frequency. Initially the antenna (of choice) is observed to resonate at $5.7 \mathrm{GHz}$, however the resonant frequency is shifted to $3 \mathrm{GHz}$ on the usage of DGS based antenna, DGS is meant to improve the circuit performance of each antenna. Radiation and surface wave losses are considered by including a parallel resistance $\mathrm{R}$ in equivalent circuit.

The equivalent admittance of parallel resonance is given by Equation

$\mathrm{Y}=(1 / \mathrm{R})+\mathrm{j} 2 \pi\left(\mathrm{C}_{\mathrm{f}}-\left(1 / 4 \pi 2 \mathrm{~L}_{\mathrm{f}}\right)\right)$

Since $Z=1 / Y$, then the equivalent impedance is given by

$\left.\mathrm{Z}=1 /(1 / \mathrm{R})+\mathrm{j} 2 \pi\left(\mathrm{C}_{\mathrm{f}}-\left(1 / 4 \pi 2 \mathrm{~L}_{\mathrm{f}}\right)\right)\right)$

In order to compute the equivalent circuit parameters $(R$, $\mathrm{L}$, and $\mathrm{C}$ ), following expressions are used:

$\mathrm{S}_{21}=1 /\left(1+(1 / 2) \mathrm{ZZ}_{0}-1\right)$

$$
S_{21}=2 Z_{0} /\left(2 Z 0+\left((1 / R)+j 2 \pi\left(C_{f}-\left(1 / 4 \pi 2 L_{f}\right)\right)\right)-1\right)
$$

Supposing that $\mathrm{R}>\mathrm{Z}_{0}$, we obtain:

$\mathrm{S}_{21}=2 \mathrm{Z}_{0} /\left(2 \mathrm{Z}_{0}+\left(\mathrm{j} 2 \pi\left(\mathrm{C}_{\mathrm{f}}-\left(1 / 4 \pi 2 \mathrm{~L}_{\mathrm{f}}\right)\right)\right)-1\right)$

At $-3 \mathrm{~dB}$ corresponding to the cutoff frequency $\mathrm{f}_{\mathrm{c}}$ can be obtained as

$\mathrm{S}_{21}=1.414$

Using Equations (5) and (6), capacitance and inductance of the equivalent circuit can be concluded as

$\mathrm{C}=\mathrm{W}_{\mathrm{c}} /\left(2 \mathrm{Z}_{0}\left(\mathrm{~W}_{02}-\mathrm{W}_{\mathrm{c} 2}\right)\right)$

$\mathrm{L}=\left(2 \mathrm{Z}_{0}\left(\mathrm{~W}_{02}-\mathrm{W}_{\mathrm{c} 2}\right)\right) / \mathrm{W}_{0} \mathrm{~W}_{\mathrm{c}}$

Resistance $\mathrm{R}$ in the equivalent circuit is best fitted around resonant frequency.

In this case, if the equivalent impedance $Z_{\mathrm{e}}=\mathrm{R}$, we have:

$\mathrm{S}_{21} \mid\left(\mathrm{W}=\mathrm{W}_{\mathrm{o}}\right)=2 \mathrm{Z}_{0} /\left(2 \mathrm{Z}_{0}+\mathrm{Z}_{\mathrm{e}}\right)=2 \mathrm{Z}_{0} /\left(2 \mathrm{Z}_{0}+\mathrm{R}\right)$

Then,

$$
\mathrm{R}=\left(2 \mathrm{Z}_{0}\left(1-\mathrm{S}_{21} \mid \mathrm{W}_{0}=\mathrm{W}_{\mathrm{e}}\right)\right) / \mathrm{S}_{21} \mid\left(\mathrm{W}=\mathrm{W}_{\mathrm{o}}\right)
$$

The design specifications for the proposed antenna are:

The dielectric material selected for the design isFR4.

Dielectricconstant 4.4

Height of substrate $(\mathrm{h})=1.57 \mathrm{~mm}$.
A compact patch antenna is designed on a FR-4 epoxy substrate having dielectric constant $\left(\varepsilon_{\mathrm{r}}\right)$ equal to 4.4. Fig.2 shows the HFSS layout of Inset feed slotted patch antenna. Parameters like patch Length \& Width are shown in the design of rectangular microstrip patch antenna, and calculated from the equations [9-14]

Step I: Substrate Dielectric constant: 4.4

Step II: Frequency of operation: $2.4 \mathrm{GHz}$

Step III: Calculation of Width of Patch (W),

Where, $\mathrm{C}=3 \times 10^{\wedge} 8, \in_{r}=4.4, \mathrm{f}_{\mathrm{o}}=5.5 \mathrm{GHz}$,

Width of Patch

$$
W=\frac{c}{2 f_{r} * \sqrt{\epsilon_{e f f}+1 / 2}}
$$
$\left(\varepsilon_{\mathrm{r}}\right)$ :

Step IV: Calculation of the Effective dielectric constant

Equation (9) gives the effective dielectric constant As:

$$
\epsilon_{\text {eff }}=\frac{\in_{r}+1}{2}(1+0.3 * h)
$$

Step V: Calculation of the Length of Strip (Ls):

The length of the Microstrip Antenna given by the equation (10)

$$
L s=\frac{0.42 * c}{f_{r} * \sqrt{\epsilon_{e f f}}}
$$

Step VI: Calculation of the Width of Ground plane $\left(\mathrm{W}_{\mathrm{g}}\right)$ :

The width of the ground plane can be calculated by the equation (11)

$$
W_{g}=\frac{1.38 * c}{f_{r} * \sqrt{\epsilon_{e f f}}}
$$

Step VII: Calculation of the Length of Ground plane $\left(\mathrm{L}_{\mathrm{g}}\right)$ :

Here the length of the ground plane is obtained by equation (12)

$$
\operatorname{Lg}=\frac{0.36 * c}{f_{r} * \sqrt{\epsilon_{\text {eff }}}}
$$

Step VIII: Calculation of the Resonant Frequency $\left(\mathrm{f}_{\mathrm{r}}\right)$ :

$$
f_{r}=3+\frac{2}{\sqrt{\epsilon_{\text {ref }}}}\left[\frac{21}{L s}+\frac{65}{W g}+\frac{18}{L g}-3\right]
$$

Resonant frequency (fr) is given by the equation

\section{SIMULATION USING HFSS}

Proposed Micro strip patch antenna was designed by using HFSS simulator. The performances are observed by comparing the Return loss, VSWR and Gain.

\section{(i)Micro Strip Patch Antenna with SLOT and without DGS}

The design corresponding to Micro strip patch antenna with SLOT and without DGS as simulated in HFSS is shown in fig. 1. The Return loss, VSWR and Gain results are observed at $5.7 \mathrm{GHz}$. 


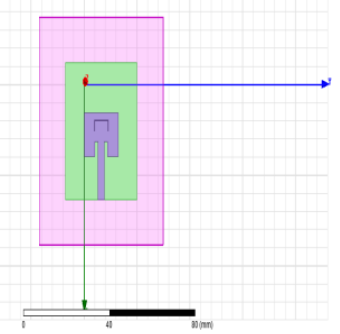

Fig.1: Front view structure of the simulated micro strip patch antenna with SLOT and without DGS

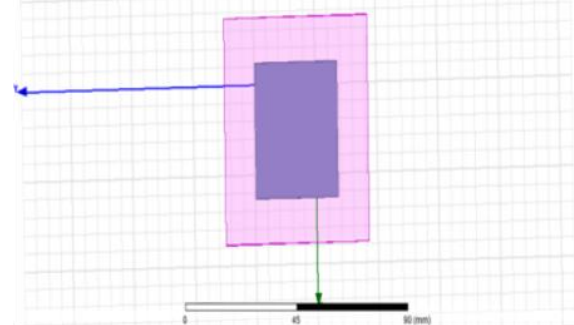

Fig. 2: Back view structure of simulated micro strip patch antenna with SLOT and without DGS

\section{(ii) Micro Strip Patch Antenna with SLOT and DGS}

The Micro strip patch antenna with one cell of DGS and SLOT is simulated in HFSS and corresponding design is shown in fig. 3 \& 4. The Return loss, VSWR and Gain results are observed at $3.75 \mathrm{GHz}$.

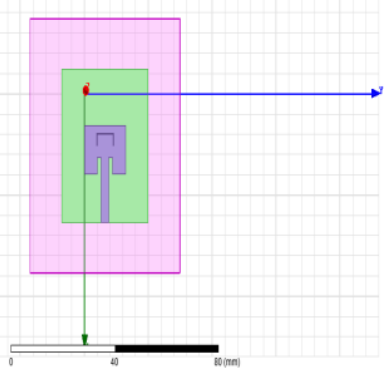

Fig.3: Front View Structure for micro strip patch antenna one cell of DGS and SLOT

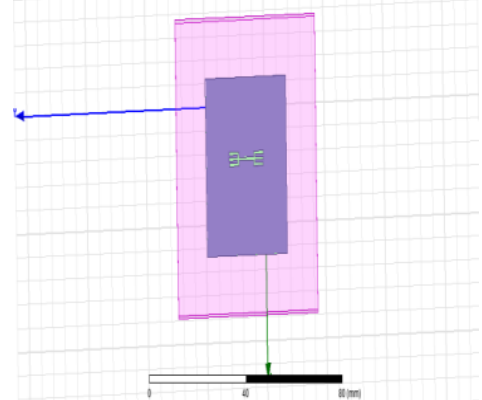

Fig.4: Back View Structure for micro strip patch antenna one cell of DGS and SLOT

\section{RESULTS}

A. Simulation Results

(i) Micro Strip Patch Antenna with SLOT and without $D G S$

The return loss for micro strip patch antenna with SLOT and without DGS is shown in fig.3.

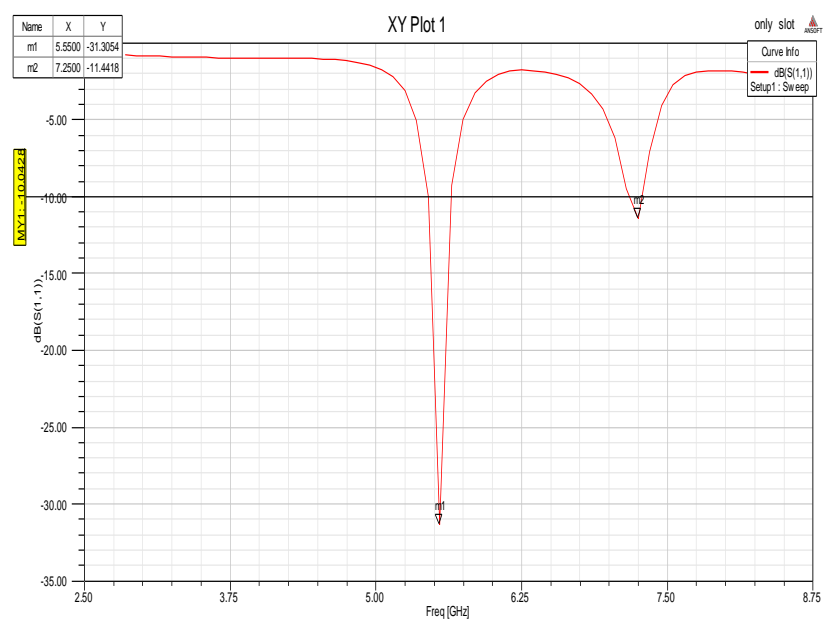

Fig 5: Return loss for micro strip patch antenna with SLOT and without DGS

From figure 5, the return loss is observed to be $-31.3 \mathrm{~dB}$ at $5.5 \mathrm{GHz}$ and $-11.44 \mathrm{~dB}$ at $7.25 \mathrm{GHz}$.Simulation results of micro strip patch antenna with SLOT and without DGS is shown in fig.4. The VSWR value at $5.5 \mathrm{GHz}$ is 1.44 and at $5.5 \mathrm{GHz}$ it is 1.43 , and the same range below $-10 \mathrm{~dB}$ return loss is below VSWR $=2$.

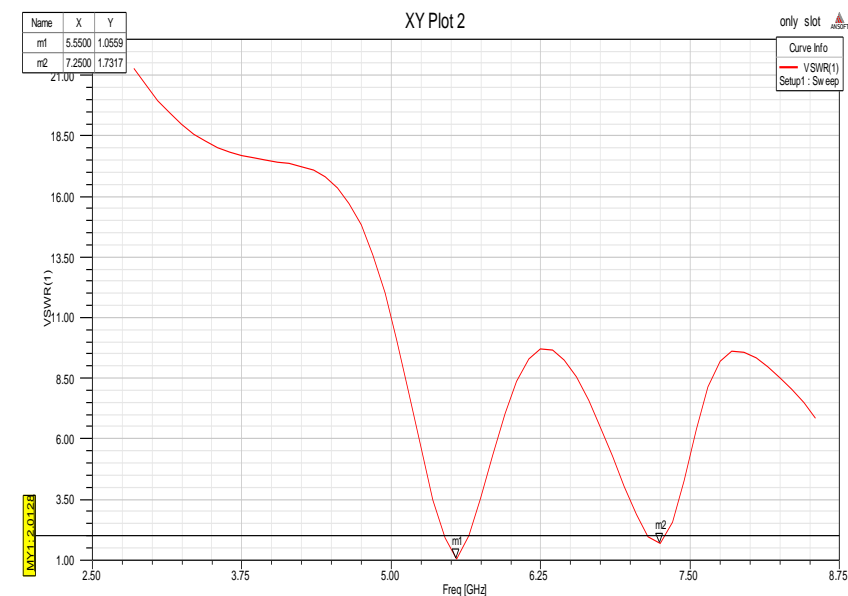

Fig.6: VSWR for micro strip patch antenna with SLOT and without DGS

The 3-D gain of micro strip patch antenna with SLOT and without DGS as shown in fi.7: is observed to be around $4.61 \mathrm{~dB}$
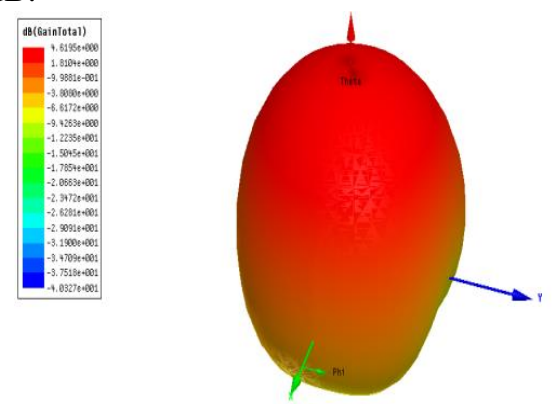

Fig.7: 3D-GAIN for micro strip patch antenna with SLOT and without DGS

Radiation pattern of micro strip patch antenna with SLOT and without DGS is shown in fig.8.

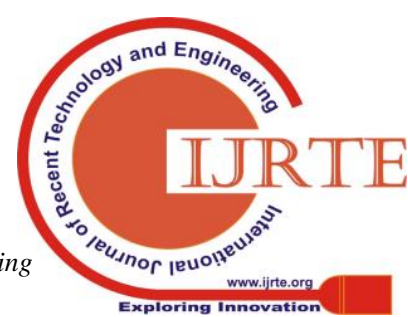



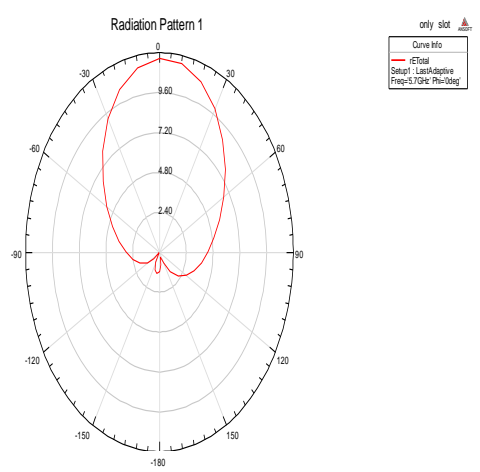

Fig.8: Radiation pattern for micro strip patch antenna with SLOT and without DGS

Smith chart for micro strip patch antenna with SLOT and without DGS as show in the figure 9.
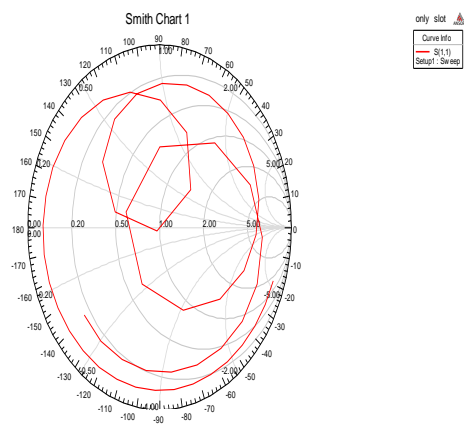

Fig.9: Smith chart for micro strip patch antenna with SLOT and without DGS

Polarization for micro strip patch antenna with SLOT and without DGS is shown in figure 10.

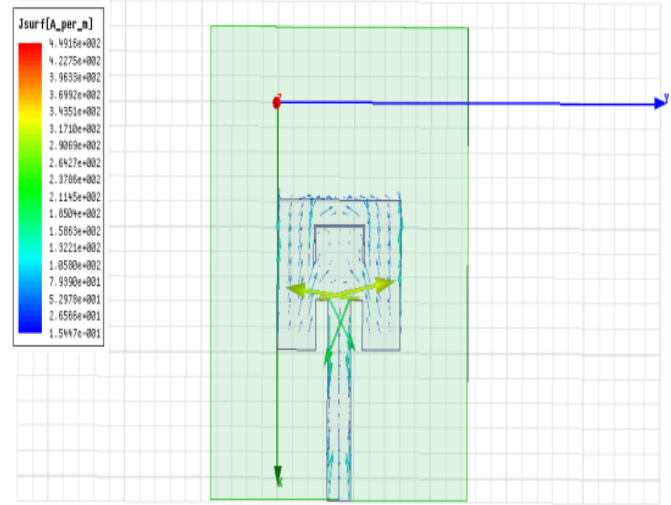

Fig.10: Polarization for micro strip patch antenna with SLOT and Without DGS

The Current Distribution depicting the front view of micro strip patch antenna with SLOT and without DGS is shown in fig. 11 .

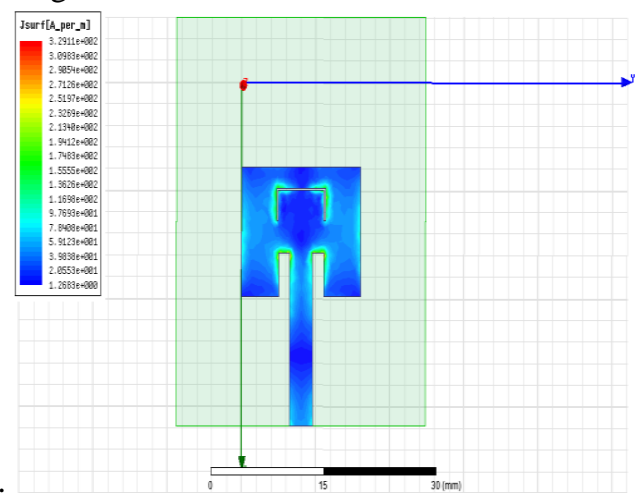

Fig.11: Current Distribution for Front view of the micro strip patch antenna with SLOT and without DGS (ii) Micro Strip Patch Antenna with SLOT and DGS

(iii)Return Loss

The return loss is another way of expressing mismatch. The return loss for micro strip patch antenna with one cell of DGS and SLOT is as shown in fig. 12.

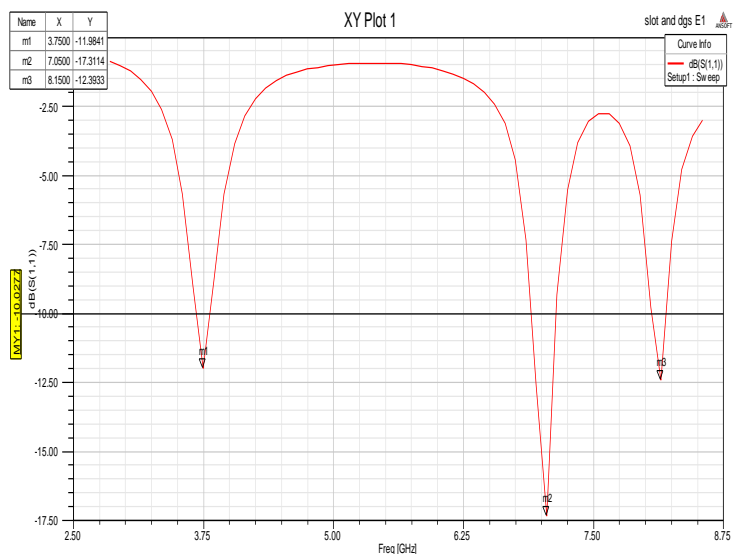

Fig.12: Return loss for micro strip patch antenna with one cell of DGS and SLOT

From this figure it is observed that the return loss as $11.98 \mathrm{~dB}$ at $3.75 \mathrm{GHz},-17.31 \mathrm{~dB}$ at $7.05 \mathrm{GHz}$, and $-12.39 \mathrm{~dB}$ at $8.15 \mathrm{GHz}$

\section{(iv).VSWR}

The VSWR is basically a measure of the impedance mismatch between the transmitters and antenna. The simulation result of micro strip patch antenna with one cell of DGS and SLOT is shown in fig. 13.

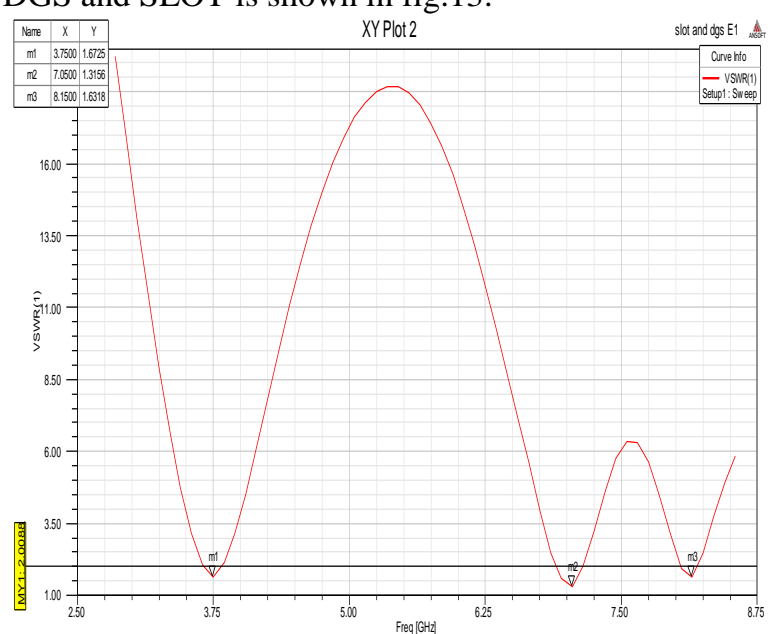

Fig.13: VSWR for micro strip patch antenna with one cell of DGS and SLOT

For practical applications, it should be in between 1 and 2. It is observed that the VSWR at $3.75 \mathrm{GHz}$ is 1.67 , at $7.05 \mathrm{GHz}$ is 1.31 and at $8.15 \mathrm{GHz}$ is 1.63 . And the same range below $-10 \mathrm{~dB}$ return loss is also below VSWR $=2$.

\section{(v) $3 D-G A I N$}

Gain is nothing but the power transmitted per unit solid angle. The 3-D gain of the micro strip patch antenna with one cell of DGS and SLOT is as shown in the Fig. 14. The Gain observed for this antenna is $1.83 \mathrm{~dB}$.

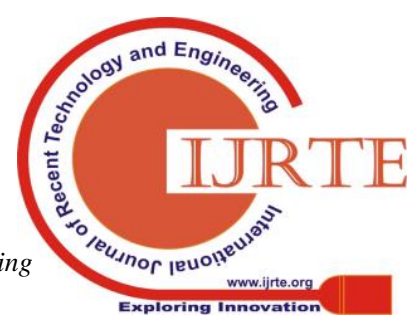




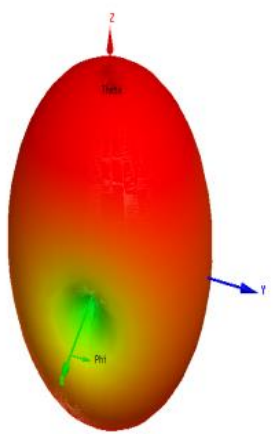

Fig.14: 3D-GAIN for micro strip patch antenna with one (vi) Radiation Pattern cell of DGS and SLOT

A radiation pattern defines the variation of the power radiated by an antenna as a function of the direction away from the antenna. This power variation as a function of arrival angle is observed in antenna's far field. The radiation pattern of micro strip patch antenna with one cell of DGS and SLOT is shown in the fig. 15.
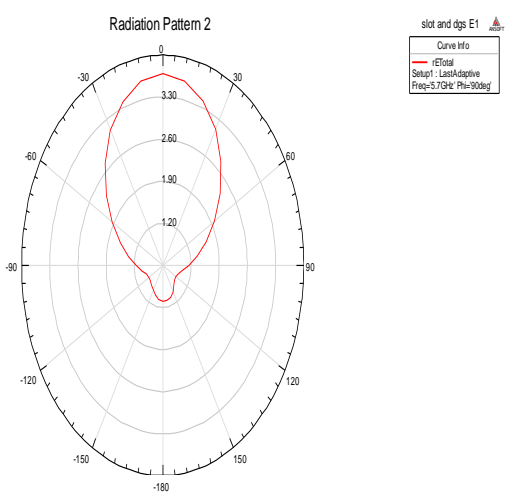

Fig.15: Radiation Pattern for micro strip patch antenna with one cell of DGS and SLOT

\section{(vii) Smith Chart}

The smith chart is a valuable graphical tool for solving radio frequency transmission line problems. Under matched impedance condition the value of reflection coefficient is 0 and that of VSWR is 1.in almost all transmission line problems, the main objective is to match the impedances of line to that with load.

The smith chart is basically a polar plot of the reflection coefficient $\mathrm{K}$ expressed in terms of normalized impedance. The Smith chart for the micro strip patch antenna with one cell of DGS and SLOT is shown in the figure 16.
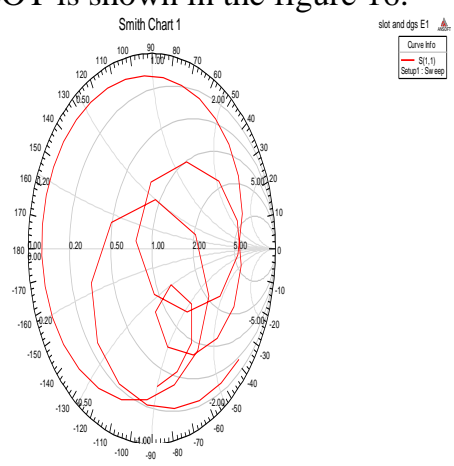
one cell of DGS and SLOT
Fig.16: Smith Chart for micro strip patch antenna with

\section{(viii) Axial Ratio}

The axial ratio is the ratio of orthogonal components of an E-field. A circularly polarized field is made up of two orthogonal E-field components of equal amplitude (and 90 degrees out of phase). Because the components are equal magnitude, the axial ratio is 1 (or $0 \mathrm{~dB}$ ). The Axial Ratio of the micro strip patch antenna without SLOT and with DGS is as shown in the Fig17.

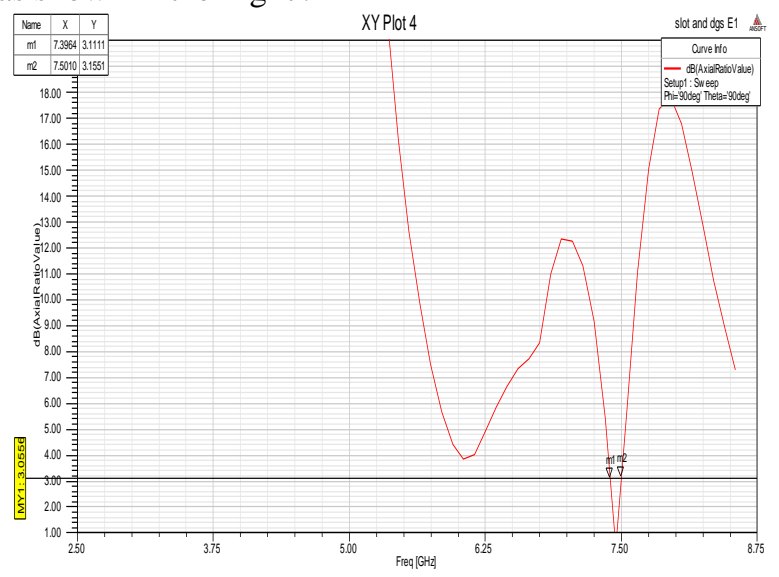

Fig.17: Axial ratio for micro strip patch antenna with one cell of DGS and SLOT

\section{(ix) Polarization}

Polarization for the micro strip patch antenna with one cell of DGS and SLOT is shown in the figure $18 \& 19$.

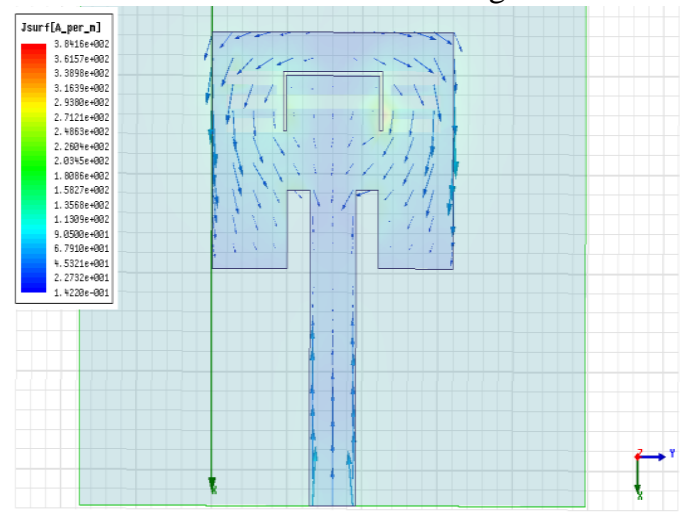

Fig.18: Polarization Front View for micro strip patch antenna with one cell of DGS and SLOT

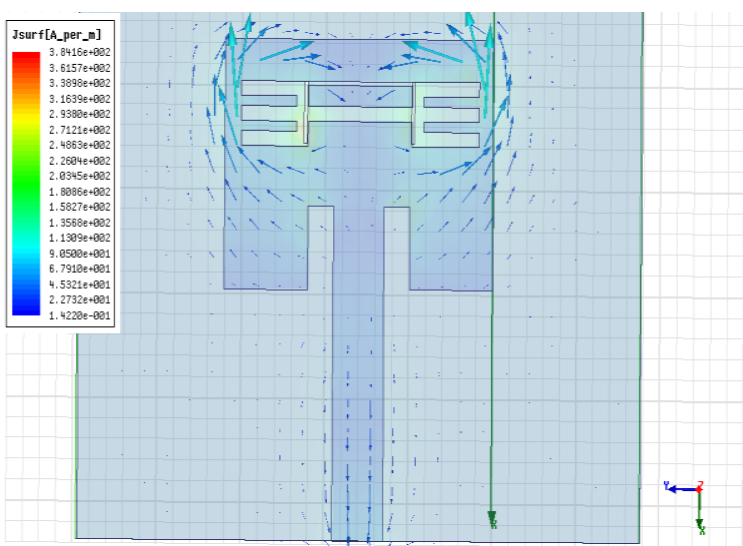

Fig.19: Polarization Front View for micro strip patch antenna with one cell of DGS and SLOT

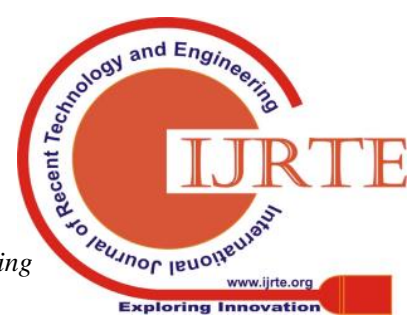




\section{DESIGN AND RESEARCH OF MINIATURIZED MICRO STRIP SLOT WITH AND WITHOUT DEFECTED \\ GROUND STRUCTURE}

\section{(x) Current Distribution}

Current Distribution for Front and Back View of the is shown in the figure $20 \& 21$.

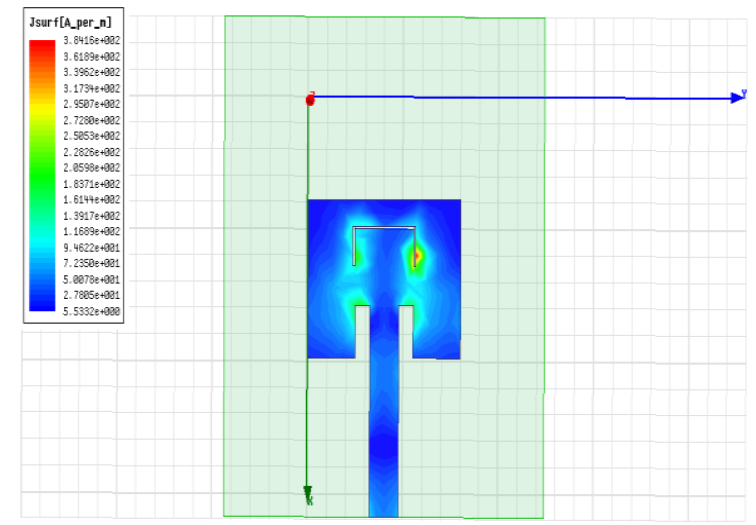

Fig.20: Current Distribution for Front view of the micro strip patch antenna with one cell of DGS and SLOT

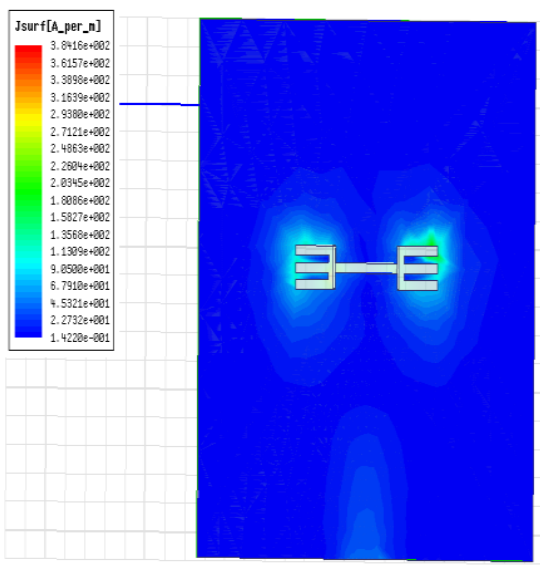

Fig.21: Current Distribution for Back view of the micro strip patch antenna With one cell of DGS and SLOT

\section{B) Measured Results}

Basic microstrip patch antennas with DGS SHAPES of L and $\mathrm{T}$ meeting all criteria required to be met by a practically applicable antenna are fabricated.

(i) Micro Strip Patch Antenna with SLOT and without $D G S$

Return loss $\rightarrow$ Return loss for micro strip patch antenna with SLOT and without DGS is shown in fig. 22.

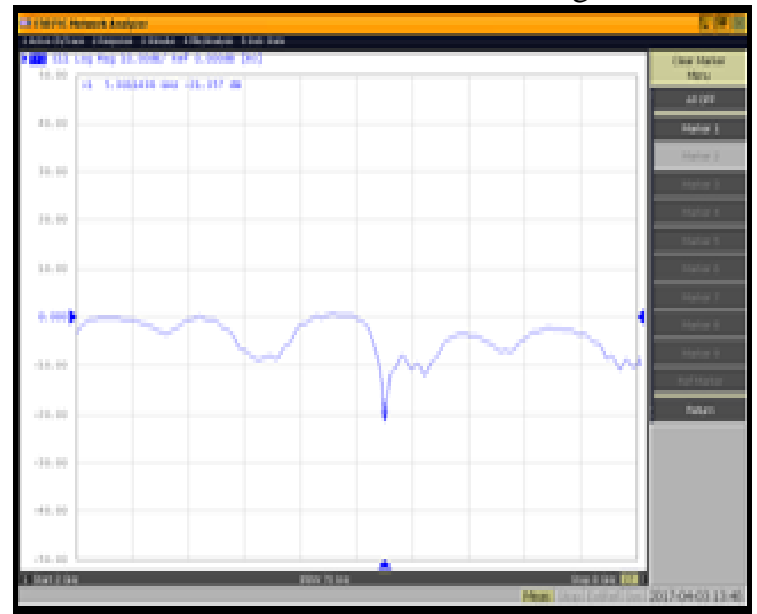

Fig. 22: Measured return loss for micro strip patch antenna with SLOT and without DGS micro strip patch antenna with one cell of DGS and SLOT

SWR $\rightarrow$ SWR for micro strip patch antenna with SLOT and without DGSis shown in fig. 23.

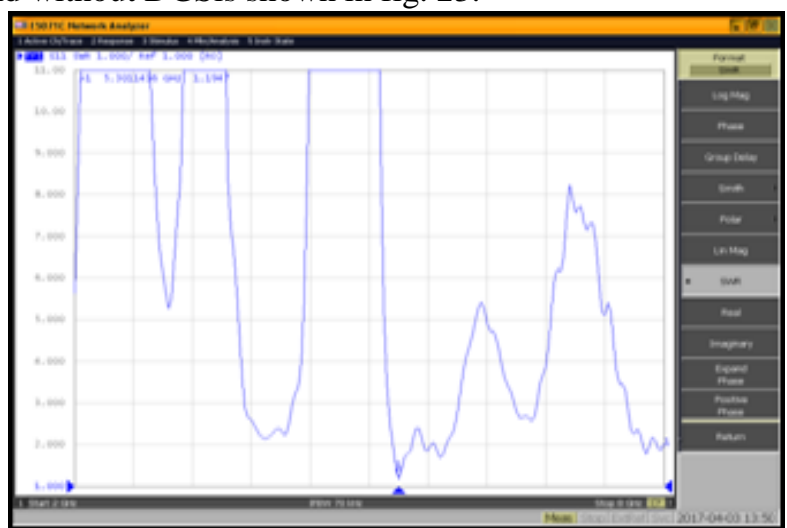

Fig. 23: Measured SWR for the micro strip patch antenna with SLOT and without DGS

Smith chart $\rightarrow$ Smith chart for micro strip patch antenna with SLOT and without DGSis shown in fig. 24.

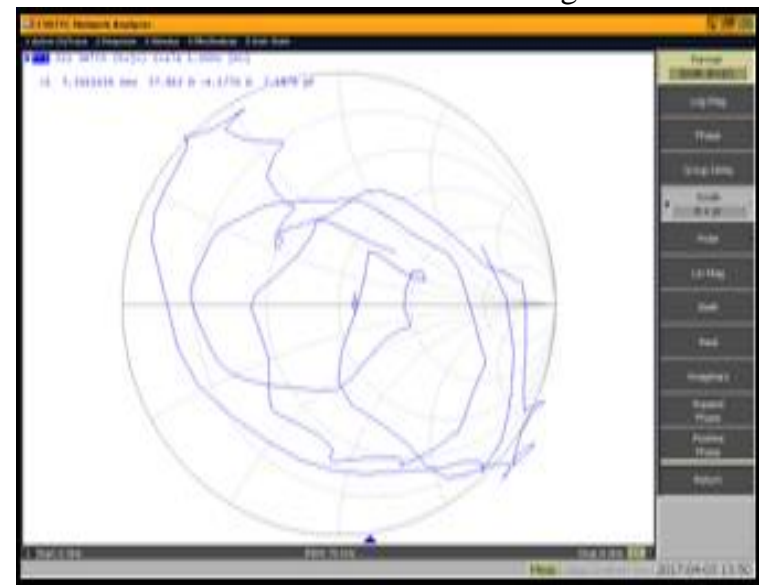

Fig.24: Smith chart for micro strip patch antenna with SLOT and without DGS

(ii) Micro strip patch antenna with SLOT and DGS

The Micro strip patch antenna with DGS and with SLOT tested in vector network analyzer (E5071C) is shown in Fig. 25 .

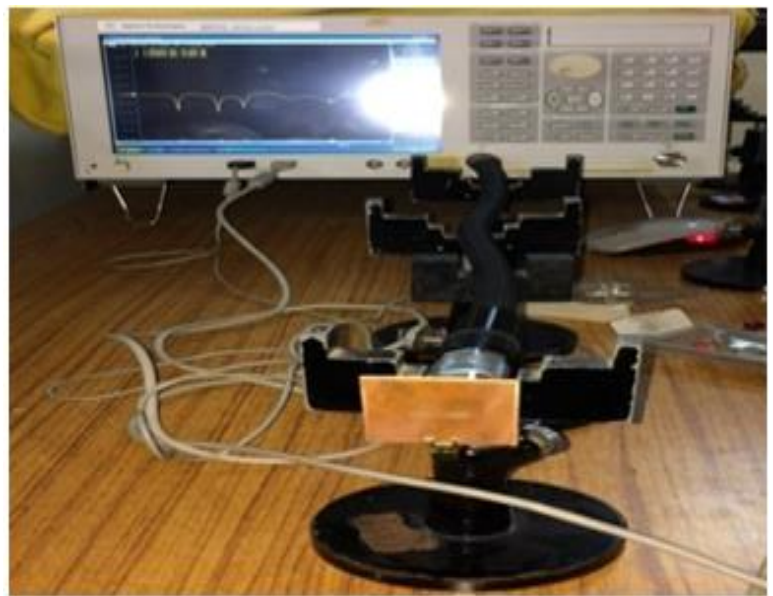

Fig.25: Experimental setup for micro strip patch antenna with DGS and with SLOT

Return loss $\rightarrow$ Return loss for micro strip patch antenna with DGS and with SLOT is shown in fig 26.

\section{Published By:}

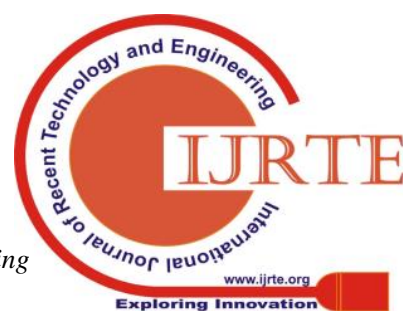




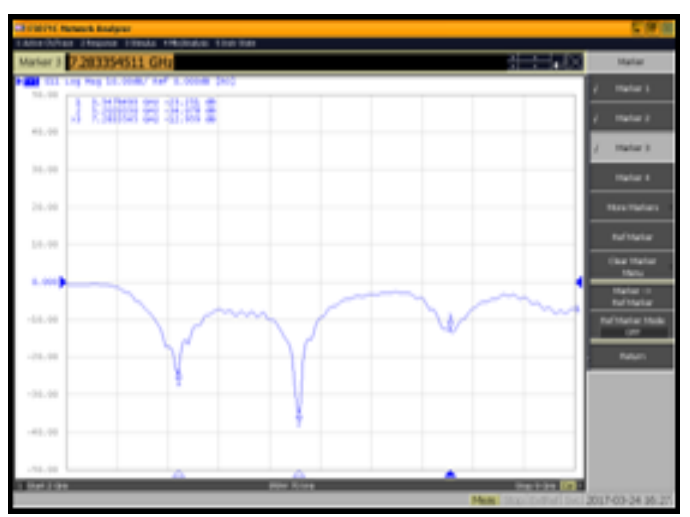

Fig. 26: Measured return loss for micro strip patch antenna with DGS and with SLOT

SWR $\rightarrow$ SWR for micro strip patch antenna with DGS and with SLOT is shown in fig 27.

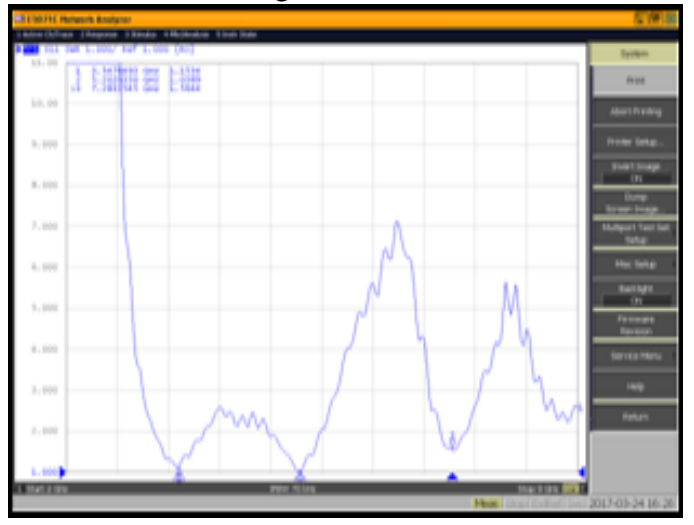

Fig.27: Measured SWR for micro strip patch antenna with DGS and with SLOT

Smith chart $\rightarrow$ Smith chart for microstrip patch antenna with DGS and with SLOT is shown in fig. 28

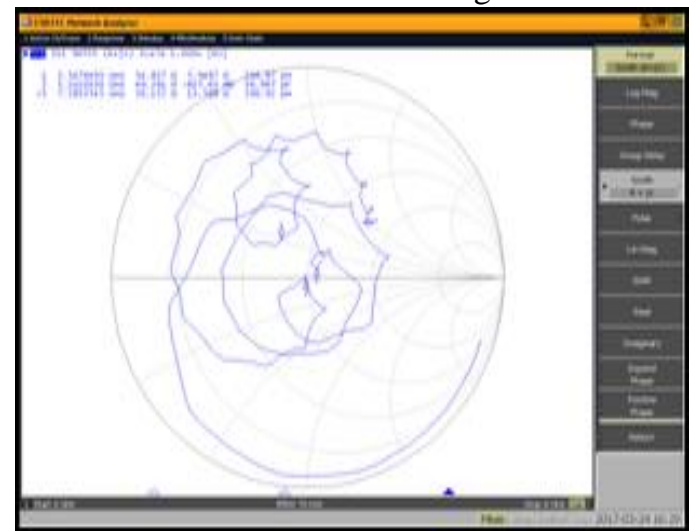

Fig. 28: Smith chart for micro strip patch antenna with DGS and with SLOT

\begin{tabular}{|c|c|c|c|c|c|c|c|c|}
\hline \multirow[t]{2}{*}{$\begin{array}{l}\text { Sl. } \\
\text { No. }\end{array}$} & \multirow[t]{2}{*}{$\begin{array}{c}\text { Microst } \\
\text { rip } \\
\text { patch } \\
\text { antenna }\end{array}$} & \multicolumn{2}{|c|}{$\begin{array}{c}\text { Frequency } \\
\text { of } \\
\text { operation(G } \\
\text { Hz) } \\
\end{array}$} & \multicolumn{2}{|c|}{$\begin{array}{l}\text { Return loss } \\
\text { (dB) }\end{array}$} & \multicolumn{2}{|c|}{ VSWR } & \multirow[t]{2}{*}{$\begin{array}{l}\text { Gain } \\
\text { (dB) }\end{array}$} \\
\hline & & Sim. & $\begin{array}{l}\mathrm{Me} \\
\text { as. }\end{array}$ & Sim & Meas. & Sim & Meas. & \\
\hline 1. & $\begin{array}{c}\text { With } \\
\text { SLOT } \\
\text { and } \\
\text { Without } \\
\text { DGS }\end{array}$ & $\begin{array}{l}5.55 \\
7.25\end{array}$ & 5.31 & $\begin{array}{l}-31.30 \\
-11.44\end{array}$ & -21.3 & $\begin{array}{l}1.05 \\
1.73\end{array}$ & 1.19 & 4.61 \\
\hline 2. & $\begin{array}{l}\text { With } \\
\text { SLOT } \\
\text { and } \\
\text { with } \\
\text { DGS }\end{array}$ & $\begin{array}{l}3.75 \\
7.05 \\
8.15\end{array}$ & $\begin{array}{l}3.54 \\
5.20 \\
7.28\end{array}$ & $\begin{array}{l}-11.98 \\
-17.31 \\
-12.39\end{array}$ & $\begin{array}{l}-23.25 \\
-34.07 \\
-12.95\end{array}$ & $\begin{array}{l}1.67 \\
1.31 \\
1.63\end{array}$ & $\begin{array}{l}1.15 \\
1.03 \\
1.56\end{array}$ & 1.83 \\
\hline
\end{tabular}

Table 1. Comparasions between With SLOT and without DGS, With SLOT and with DGS

\section{CONCLUSION}

The miniaturization procedure initiated with a typical rectangular patch shaped array antenna with DGS gives a size reduction up to $59 \%$ asthe resonance frequency of the initial antenna without DGS has been shifted from $5.5 \mathrm{GHz}$ to $7.25 \mathrm{GHz}$. To achieve miniaturization without much degradation of antenna performance, further the patch radiator is modified keeping the physical volume of the antenna constant with the same DGS structure to retain its radiation properties which gives a size reduction of the initial antenna without DGS has been shifted from $5.2 \mathrm{GHz}$ to $7.25 \mathrm{GHz}$. In this way it has been able to reduce the maximum antenna size up to $59 \%$ as compared to conventional antenna without much degradation of the performance of the antenna.

\section{REFERENCES}

1. C.A. Balanis, Antenna Theory: Analysis and Design, John Wiley \& Sons Inc., 1997.

2. D. Nashaat, H. Elsadek, H. Ghali, Multiband miniaturized PIFA for compact wireless communication applications, Microwave Opt. Technol. Lett. 42 (3) (2004) 230-235.

3. T.K. Lo, Y. Hwang, Microstrip antennas of high permittivity for personal communication, in: 1997 Asia Pacific Microwave Conference, 1997, pp. 253- 256.

4. J.A. Tirado-Mendez, M.A. Peyrot-Solis, H. Jardon-Aguilar, E.A. AndradeGonzalez, M. Reyes-Ayala, Applications of novel defected microstrip structure (DMS) in planar passive circuits, in: Proceedings of the 10thWSEAS International Conference on CIRCUITS, Vouliagmeni, Athens, Greece, July 10-12, 2006, pp. 336-369.

5. M. Chakraborty, B. Rana, P.P. Sarkar, A. Das, Size reduction of microstrip antenna with slots and defected ground structure, Int. J. Electron. Eng. 4 (1) (2012) 61-64.

6. L.H. Weng, Y.C. Guo, X.W. Shi, X.Q. Chen, An overview on defected ground structure, Prog. Electromagnet. Res., B 7 (2008) 173-189.

7. HanaeElftouhl, Naima A. Touhami, Mohamed Aghoutane, Miniaturized microstrip patch antenna with defected ground structure, Prog. Electromagnet. Res., C 55 (2014) 25-33.

8. F. Yang, Y. Rahmatsamii, Electromagnetic Band Gap Structures in Antenna Engineering, Cambridge University Press, USA, 2009.

9. Munish Kumar, VandanaNath, Analysis of low mutual coupling compact multi-band microstrip patch antenna and its array using defected ground structure, Eng. Sci. Technol. Int. J. (2015). jestch.2015.12.003.

10. Ashwini K. Arya, M.V. Kartikeyan, A. Patnaik, Defected ground structure in the perspective of microstrip antenna, Frequenz 64 (5-6) (2010) 79-84.

11. A.K. Arya, A. Patnaik, M.V. Kartikeyan, Microstrip patch antenna with skew-F shaped DGS for dual band operation, Prog. Electromagnet. Res., M 19 (2011) 147-160.

\section{AUTHOR DESCRIPTION}

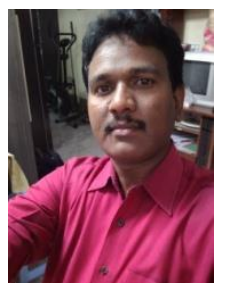

D. Nataraj completed M.Tech.in the stream of ECE. (Digital System and Computer Electronic) in the year 2009 from JNTU Hyd. College of Engg. JNTUH. $\mathrm{He}$ is working as Assoc. professor in Pragati Engineering College

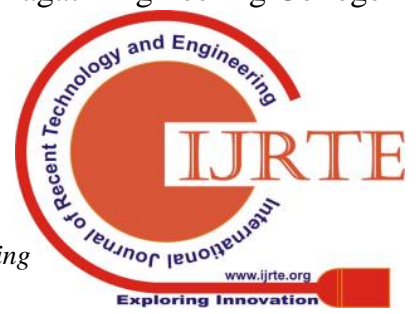


(A3), Kakinada India. He is the Life member of IETE. He is published several papers in Microstrip Antennas. His area of interests is Antenna and propagation, EM fields and Microwave Engineering.

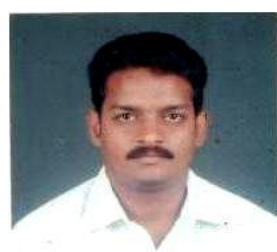

Dr. G. Karunakar completed his B.E. and Master of Engineering in the stream of Electronics and communication Engineering and Microwave and Radar engineering in the year of 1985, 1987 respectively. He obtained his $\mathrm{PhD}$ from Andhra University in 2012.

Now, he is working as Associate Professor in GITAM Institute of Technology, GITAM Deemed UniversityVisakhapatnam and India. He has more than 30 years Teaching \& Research Experience. His area of interests is Antenna and propagation, Microwave and Radars. 